\title{
Do Oil Price Shocks Affect Household Consumption?
}

\author{
Nabila Zaman ${ }^{1, *}$ \\ ${ }^{1}$ Department of Economics, East West University, A/2, Jahurul Islam Avenue, Dhaka 1212, \\ Bangladesh \\ *Corresponding author: E-mail: nabila@ewubd.edu \\ This paper was originally written as part of her Master thesis at Lund University.
}

Received: October 27, 2018 Accepted: January 2, 2019 Published: March 20, 2019

doi: 10.5296/rae.v11i1.13826 URL: https://doi.org/10.5296/rae.v11i1.13826

\begin{abstract}
The paper addresses whether international oil price change has any impact on consumer spending. The study is conducted using Organisation for Economic Co-operation and Development nations, which have been chosen deliberately based on their economic importance and classifying each into oil importing and exporting countries: Canada, Germany, the UK and the USA. Applying the empirical methodology of the vector autoregressive model, we find evidence that international oil price shocks have a significant impact on consumer spending. The analysis is performed with two sets of specification for oil ('Oil price change' and 'Net oil price increase') and the main tools used for diagnosis are forecast error variance decomposition and impulse-response functions.

The results are strongly significant for Canada and the USA. The results for Germany and the UK are mixed, which leads us to an inconclusive decision about the impact on these countries. However, in general, our empirical work supports the evidence that oil prices have some predictive power in influencing consumption decisions across oil-importing and oil-exporting countries.
\end{abstract}

Key words: Oil price shock, Vector Autoregressive Model, Household consumption, OECD 


\section{Introduction}

Oil is an important component of the global economy. Historical oil price shocks caused by demand or supply gaps have been seen to affect the economies of not only oil producers but also oil consumers in general. Historically, most of the oil price shocks arose from political conflicts or supply gaps. The history of oil price shocks dates back to the 1970s when the world experienced its first oil shock in 1973 as a result of a reduction in oil exports by the oil-producing countries, followed by political conflicts emerging among the 'Organization of the Petroleum Exporting Countries' nations in 1979. Throughout these periods, oil prices rose much higher than the existing market price, causing many of the leading developed nations to suffer. Another oil crisis began in 2003 when the price of crude oil started rising and peaked at its highest value in 2008. The main reason behind this was the increase in global demand for oil in response to existing supply. Since November 2014, a lack of global demand against the current production of oil caused the international oil price to fall drastically. Thus oil price shocks have always been associated with business cycles across the globe, where both oil-producing and consuming countries have been severely affected.

Although oil price shocks can have direct impacts on macroeconomic indicators such as exchange rates, balance of payments, export/imports, interest rates, which can allow us to measure its impact on economic growth, how it affects consumers is not straightforward to assess. When there is a shock in the economy, the expectations of consumers about the persistence of the shock will be reflected in both their current and future consumption patterns. This, in turn, will have other economic consequences affecting decisions for wage-earners as well as industrialists.

Thus this study aims to empirically assess if oil price shocks have had any impact on household consumption over last two decades. Because of the increased importance of oil prices globally, there have been very many studies on how oil prices affect the macroeconomic activities of both large oil-importing and oil-exporting nations. If there is an oil crisis, its effect is likely to be felt more quickly in the oil-exporting countries than the oil-importing countries or the countries least dependent on oil. This may be reflected in the form of job losses or changes in interest rates and/or exchange rates. However, the impacts are not homogenous for all countries. This study chose to conduct empirical work focusing on the Organisation for Economic Co-operation and Development (OECD) region. The reason for this is the increasing importance and fast growth of the OECD member nations since the 1960s, which created massive demand for energy as they flourished into large industrial countries. The huge demand caused unparalleled pressure on the regional energy market leading to subsequent policy changes over the years. Therefore, this study deliberately selected four OECD nations: Canada as a net exporter, and Germany, the UK and the USA as net oil-importers(Note 1). As proposed by Mehra \& Petersen (2005), the study applies the empirical vector autoregressive model (VAR) approach to assess the impact of oil prices on household consumption. 


\section{Literature Review}

A wide range of literature on oil prices tends to focus on its implications on overall macroeconomic activities. This includes impacts on the money market, exchange rates, economic growth and international trade between oil-importing and oil-exporting countries, reflecting their impact in the aftermath of oil price shocks (Herrera, Lagalo, \& Wada, 2015; Jiménez-Rodríguez\& Sánchez, 2005; Mork, 1989). The study by Mork(1989) also studied the effects of fluctuations in oil price shocks on gross domestic product growth for some OECD countries. The results seem to have varied a lot from country to country. However, one common observation in each of these studies was that the effects of an oil price change were significantly larger for the heavily oil-dependent countries.

Although most of the literature emphasizes how oil price changes affect economic activities in general, only a handful of studies talk about its effects on household consumption. In this regard, Blanchard \& Gali (2007), Kilian (2008), Mehra \& Petersen (2005) were the first to study the impact of oil prices on household consumption. However, each of these took a different approach towards how the oil price enters the consumption of individuals and discusses its implications differently.

For instance Mehra \& Petersen (2005) adopted the famous 'life-cycle' model of consumption by Modigliani \& Brumberg (1954) to empirically study if the oil price affected the total consumption of households in the USA. They study the direct impact of oil price changes within the model, with other variables (wealth, income and interest rates) serving as control variables and using a vector error-correcting model. Based on the empirical results, they found evidence that the oil price significantly impacts consumption in the short term but not in the long term. Inspired by the work of Mehra \& Peterson (2005), Zhang \& Broadstock(2014) expanded this study by using a similar approach for some selected the Association of Southeast Asian Nations (ASEAN) and East Asian economies, which are broadly classified as oil-importing nations. However, the difference between the two papers is that Zhang \& Broadstock (2014) did not specify interest rate changes as one of the determining factors of consumption.

Blanchard \& Gali (2007) and Kilian (2008), however, took a different approach. They developed a simple model where oil was assumed to be used as an input of production and the rest was consumed by households. They showed empirically that oil prices affect consumers through increasing or decreasing the consumer price of final commodities when there is a price change. This is because a change in price of oil would make imports expensive and hence they raise the production cost of the commodities dependent on oil, thus increasing the consumer price.

There are only few studies on the consumption effects of oil price shocks. Mehra \& Petersen (2005) was first to conduct an empirical study within a standard macroeconomic context. Hence, this study is based on the empirical approach proposed by Mehra \& Petersen (2005). Although the former study was conducted on the economy of the USA between the 1960s and 2003, our study expands the work to include four OECD countries, notably Canada, which is a net exporter of oil, and Germany and UK, which are net importers of oil. We also 
include the USA, as it has been an important economy for its oil dependence since 1960s, though its status has now changed to a net importer. In addition, because we include a sample with an inflation-targeting interest rate regime, we might expect to get different results for the USA over the study period. Whereas Mehra \& Petersen (2005) used change in gasoline prices, we include changes in crude oil prices to conduct our study. Mehra \& Petersen (2005) used the Generalized Methods of Moments (GMM) method to estimate the two major effects: 'Positive oil price increases' and 'Net oil price increases'. In this paper, the effect of oil price is calculated for the period between 1986 and 2013, which is first calculated for the whole period and then for 'net oil-price increase. Hamilton (2009) found a strong correlation between oil price hikes and growth in gross national product from the USA's perspective. However, this study did not provide any evidence of this correlation when the oil price declined. Mork (1989) also found evidence that gross national product growth is indeed correlated with increases in the oil price.

Hamilton (2009) attempted to identify the similarities and dissimilarities between oil price shocks in 2007-08 and previous oil price shocks considering the causes and consequences of these shocks. He found that the causes of oil price shocks are different and but their consequences are the same. His study revealed that oil price shocks have a significant effect on overall consumption spending.

\section{Theoretical Framework and Research Design}

The choice of countries has been deliberately selected to include of oil-importers and exporters, as well as the availability of data. The chosen countries are among the 10 largest oil importers and oil exporters according to the U.S Energy Information Administration (EIA). The study only captures the effects of changes in the price of crude oil for these countries. In this regard, data from the EIA suggest that although Canada's consumption of crude oil has increased significantly, for rest of the countries, consumption has decreased over time since 2006.

The theoretical model for this study is based on the macroeconomic life-cycle model of consumption of Modigliani \& Brumberg (1954). The main assumptions of the model are that in an economy, consumption is a function of income, wealth and the short-run interest rate. However, each of the three variables affects consumption in different ways (Sørensen \& Whitta-Jacobsen, 2010).

As Modigliani \& Brumberg (1954) described, the 'intertemporal budget constraint' states that a consumer's lifetime consumption is a function of the current period's wealth $\left(W_{t}\right)$, the current period's disposable income $\left(Y_{t}^{d}\right)$ and the flow of future income at $(t-i)$, discounted at the current rate of interest $(r)$. In other words:

$$
C_{t}+\frac{C_{t+\tilde{i}}}{(1+r)}=W_{t}+Y_{t}^{d}+\frac{Y_{t+i}^{d}}{(1-r)}
$$




\section{MlMacrothink}

Thus, by the assumptions of life-cycle theory, consumption is a function of wealth, disposable income and the real interest rate:

$$
C_{t}=f\left(Y_{t}^{d}, r_{t}, W_{t}\right)
$$

We also need to define how each of these variables affects consumption. The model assumes that real disposable income and net financial assets affect consumption positively (i.e., an increase in disposable income will increase private consumption in short term). However, the impact of the real interest rate on consumption is uncertain. The interest rate is assumed to influence consumption through two major ways: the income effect and the substitution effect (Sørensen \& Whitta-Jacobsen, 2010). This implies that a rise in interest will decrease demand for wealth, as people will spend less on acquisition of wealth. Similarly, an increase in wealth is likely to make savings more preferable than consumption. Considering this, it is expected that an individual's future income will fall and hence so will future consumption.

However, there is little empirical evidence to help us draw a general conclusion about the effects of the interest rate on consumption (Sørensen \& Whitta-Jacobsen, 2010). Mehra \& Petersen (2005) used the consumption model of Modigliani \& Brumberg (1954) to empirically study the impact of the interest rate on household consumption in the USA.

Weber (1970) studied the relationship between the interest rate and aggregate consumption using US data. He found that a rise in the interest rate increased aggregate consumption ceteris paribus. Similar results have been found by Springer (1975) that there is a positive relationship between interest rates and consumption. On the contrary, Mishkin (1976) showed an inverse relationship between the interest rate and consumption of durable goods. Gylfason (1981) examined the impact of the interest rate and inflation on aggregate consumption in the post war period in the US and found an inverse relationship between the interest rate and the aggregate propensity to consume.

To capture the effect of time on the lagged variables of income, wealth and consumption, we need to include lag for each of these in the consumption model. It is also reasonable to think that the effects of income and wealth may not be realized on consumption unless a particular period of time has elapsed. In reality, consumers tend to smooth consumption over their lifetimes, and there always remains a divergence between planned and actual consumption, which needs to be identified. In this regard, Mehra \& Petersen (2005) assumed that a rational consumer's actual consumption will always fluctuate around a planned level of consumption. This is a function of the anticipated value of lifetime resources, which equals current $\left(Y_{t}\right)$ andexpected future labor income $\left(Y_{t+k}^{e}\right)$, and the current value of financial assets $\left(W_{t}\right)$ as follows, where $C_{t}^{p}$ is planned consumption at time $(t)$ :

$$
c_{t}^{p}=a_{0}+a_{1} Y_{t}+a_{2} Y_{t+k}^{e}+a_{3} W_{t}
$$

As a result, the differences between current and planned consumption establish long-run equilibrium (Enders, 2004). 


\section{Macrothink}

Thus considering this issue, the final model of short-term consumption is as shown by Equation 2, where a change in current consumption $\left(\Delta \boldsymbol{C}_{t}\right)$ is a function of the previous period's income $\left(\Delta \boldsymbol{Y}_{t-1}\right)$, the previous period's wealth $\left(\Delta \boldsymbol{W}_{t-1}\right)$ and consumption in previous periods $\left(\Delta \boldsymbol{C}_{t-s}\right)$, and the adjustment lag between actual and planned consumer spending is reflected through introducing the error-correcting term in the equation $\left(\boldsymbol{C}_{t-1}^{p}-\boldsymbol{C}_{t-1}\right)$ as follows:

$$
\Delta C_{t}=\alpha_{0}+\alpha_{1}\left(C_{t-1}^{p}-C_{t-1}\right)+\alpha_{2} \Delta Y_{t-1}+\alpha_{3} \Delta W_{t-1} \sum_{s=1}^{k} \Delta C_{t-s}+\mu_{t}
$$

As specified in Equation (2), the error-correcting term is expected to be greater than zero. This reflects that long-run equilibrium is attained as the previous period's consumption $\left(\boldsymbol{C}_{t-1}\right)$ draws closer to the planned consumption $\left(\boldsymbol{C}_{t-1}^{p}\right)$.

One key problem to analyze econometrically in this model is the identification of expected income within planned consumption. It is not possible to observe future anticipated wealth in reality. Thus, Mehra \& Petersen (2005) made an assumption that the growth of expected income is constant over time, expressed as $\boldsymbol{Y}_{t+k}^{e}=\boldsymbol{Y}_{\boldsymbol{t}}$. Following this assumption, the specification for planned consumption changes to:

$$
c_{t}^{p}=b_{1} Y_{t}+b_{2} W_{t}+\varepsilon_{t}
$$

where $\varepsilon_{t}$ is a white noise process (Enders, 2004; Zhang \& Broadstock, 2014).

When we substituting Equation (3) into Equation (1), the final model of consumption then becomes a function of income, wealth and consumption as shown in Equation (4):(Note 2)

$$
\Delta C_{t}=\alpha_{0}+\alpha_{1}\left(\left(a_{0}+a_{1} Y_{t}+a_{2} W_{t}\right)-C_{t-1}\right)+\alpha_{2} \Delta Y_{t-1}+\alpha_{3} \Delta W_{t-1} \sum_{s=1}^{k} \Delta C_{t-s}+\mu_{t \cdot}(4)
$$

The key question is how one can assess oil price effects by using the model established above. The impact of oil price shocks on the model above is not straightforward to assess. The main assumption behind conducting this study is that energy constitutes a high percentage of household consumption. This is because of its significant use in transportation and in households, and also in the production processes of consumable products. Hence, we directly assess the impact of the oil price by adding it as an exogenous parameter in the consumption model. In order to capture the movement of short-term interest rates as a result of oil price shocks, we also include the interest rate as another exogenous variable(Note 3).

Provided the model holds true, this introduces two possibilities: the oil price may only have a short-term effect, or the oil price may have both short- and long-run causalities. If oil prices and other variables are expected to establish long-run equilibrium, then the final model 
estimation could be expressed as Equation (5):

$$
\begin{aligned}
& \Delta C_{t}=\alpha_{0}+\alpha_{1}\left(\left(a_{0}+a_{1} Y_{t-1}+a_{2} W_{t-1}+a_{3} R_{t-1}+a_{4} \text { Oil_Price }_{t-1}\right)-C_{t-1}\right)+ \\
& \alpha_{2} \Delta Y_{t-1}+\alpha_{3} \Delta W_{t-1} \sum_{s=1}^{k} \Delta C_{t-s}+\sum_{s=1}^{k} b_{4 s} \Delta \text { Oilprice }_{t-s}+\sum_{s=1}^{k} \Delta R_{t}+\mu_{t}
\end{aligned}
$$

However, without empirical tests it is not realistic to assume that global oil prices have a strong impact on consumers' decisions in the long term. Moreover, Mehra \& Petersen (2005), and Zhang \& Broadstock (2014) did not find any significant evidence of long-run equilibrium deriving from oil price changes. Thus, in alignment with previous literature, we also leave it to the empirical assessment to see if oil prices have an effect in both the short and long term. Should there be no long-run effects, model specification to be used would be a VAR; otherwise, a 'vector error-correcting model' (VECM) would be more appropriate and thus the error-correcting term in Equation (5) will eventually dropout.

\subsection{Data}

Data have been collected on private final consumption $\left(C_{t}\right)$, disposable income of household $\left(Y_{t}\right)$, net acquisition of financial asset of household $\left(W_{t}\right)$ and short-term interest rates $\left(r_{t}\right)$ from Oxford Economics Global Data Services (2015) and the Federal Reserve Bank of St. Louis (2015). This is because, unlike other sources, the research unit of Federal Reserve Bank compiles data on a quarterly basis, which is more relevant for this study. Thus data were obtained for between 1986Q1 and 2013Q4 on a national level. Since the study involves assessing the impact of oil price shocks at the consumer level, we divided the data by the total quarterly population to capture the effect at a per capita level. The data for the four countries differ as to their units of measurement. For instance, the data for Germany was in Euros but that of the UK was in pounds sterling. The data have all been converted to constant US dollars using the exchange rate of currency from Bloomberg. To capture the effects on short-term consumption, it was important to collect data on a quarterly basis.

To measure the impact of oil price shocks, data on the spot prices of West Texas Intermediate (WTI) and Brent Europe have been collected from the EIA (2015). The WTI data is relevant for Canada and the USA, whereas the Brent Europe data are more relevant for the UK and Germany (EIA).

\section{Empirical Results and Discussion}

Before establishing whether the oil price has an impact on consumer spending, it is important to study the stationarity of the variables. Given that we estimate the model in Equation (5), it must be confirmed that the variables exhibit stationarity, which, if not found, would need to be taken in first differences.

To test for a unit root, we perform the Augmented Dicky-Fuller (ADF) test for each variable both at levels and in the first and second differences, and the test results are reported in Table 


\section{Macrothink}

Research in Applied Economics

ISSN 1948-5433

2019, Vol. 11, No. 1

1. The presence of a unit root was investigated with the ADF test by running a regression using the following equation, where $x$ represents the relevant variables in our model:

$$
\Delta x_{t}=a_{0}+\gamma x_{t-1}+a_{1} t+\sum \beta_{i} \Delta x_{t-1}+\varepsilon_{t}
$$

Thus the ADF test allows one to examine presence of a unit root process with 'trend' and 'intercept' regressors, which are purely deterministic, whereas $\boldsymbol{x}_{\boldsymbol{t}-1}$ is a unit root process under the null hypothesis (Enders, 2004). The computed ADF test statistics at levels are found to be significant at the $5 \%$ level, but those at the first and second differences were found to be insignificant at the $5 \%$ or $1 \%$ levels, thus confirming that the variables are indeed non-stationary. The only exception was in the case of the wealth series for Germany, which demonstrates stationarity even at level.

In addition, we further observe that for some variables the test results were found to be stationary only with the intercept. A key problem with using the ADF test is that the intercept and slope of the trend are not well estimated in the presence of a unit root (Enders, 2004).

Therefore, the results show that the variables individually are all I(0) at first differences. In other words, they are integrated of order one. Given that the variables are individually integrated, there remains the possibility that the series of variables together may be cointegrated or exhibit a common trend in the long term although it is not a necessary condition to be held true always (Enders, 2004). As already discussed, the decision regarding which model specification to be applied depends on whether cointegration exists between the variables, and further tests are required.

With the presence of cointegration, the correct model specification to be used will then be the VECM and not a VAR. However, Mehra \& Petersen (2005) andZhang \& Broadstock (2014) found no significant evidence of long-term equilibrium, although the empirical study by Zhang \& Broadstock (2014) stated that cointegration exists among the consumption, income and wealth series, which is also what one might expect theoretically. Thus before proceeding further, we investigate whether consumption, income and wealth, together with oil and interest rates, are cointegrated or not. 
Table 1. Augmented Dickey Fuller Test Results.

ADF Null Hypothesis: There is a unit $\operatorname{root}(\gamma=0)$

\begin{tabular}{|c|c|c|c|c|c|}
\hline \multirow[t]{2}{*}{ Country } & \multirow[t]{2}{*}{ Variable } & \multicolumn{2}{|c|}{ ADF (at level) } & \multicolumn{2}{|c|}{ ADF (at first/second difference) } \\
\hline & & t-stat & p-values & t-stat & p-values \\
\hline Canada & $C_{t}$ & -1.379845 & 0.5896 & -3.577856 & 0.0078 \\
\hline & $Y_{t}$ & -2.790909 & 0.2039 & -4.170956 & 0.0069 \\
\hline & $W_{t}$ & -0.230991 & 0.9916 & -3.817670 & 0.0193 \\
\hline & $r_{t}$ & -1.242114 & 0.6541 & -4.293776 & 0.0047 \\
\hline \multirow[t]{4}{*}{ Germany } & $C_{t}$ & -2.790685 & 0.0630 & -3.620617 & 0.0327 \\
\hline & $Y_{t}$ & -2.501512 & 0.3269 & -3.515616 & 0.0428 \\
\hline & $W_{t}$ & -5.769046 & 0.0000 & -5.189286 & 0.0002 \\
\hline & $r_{t}$ & -1.305658 & 0.6251 & -4.136944 & 0.0076 \\
\hline \multirow[t]{4}{*}{ UK } & $C_{t}$ & 0.562583 & 0.9881 & -5.656522 & 0.0000 \\
\hline & $Y_{t}$ & -0.502661 & 0.9821 & -5.969440 & 0.0000 \\
\hline & $W_{t}$ & -1.389054 & 0.8588 & -5.623393 & 0.0000 \\
\hline & $r_{t}$ & -0.998354 & 0.7520 & -4.588081 & 0.0018 \\
\hline \multirow[t]{4}{*}{ USA } & $C_{t}$ & -1.858752 & 0.6688 & -3.459087 & 0.0110 \\
\hline & $Y_{t}$ & -2.038622 & 0.5734 & -3.813194 & 0.0195 \\
\hline & $W_{t}$ & -2.089742 & 0.5455 & -3.658345 & 0.0297 \\
\hline & $r_{t}$ & -1.405522 & 0.5772 & -3.573421 & 0.0370 \\
\hline Brent Europe & Oil price & -0.645166 & 0.8549 & -6.364396 & 0.0000 \\
\hline WTI & Oil price & -0.960736 & 0.7651 & -6.604031 & 0.0000 \\
\hline
\end{tabular}

Note: ADF (level) $t$-stats are greater than the critical values; ADF (differences) $t$-stats are less than the critical values at the $5 \%$ or $1 \%$ levels. 
A test proposed by Engle \& Granger (1987) can be used to test for cointegration. The test is a two-step process, where, in the first step, the set of variables concerned in the model is regressed, and the resulting residual is then tested to see if it exhibits stationarity or long-run equilibrium (Enders, 2004). The null hypothesis is that there is no cointegration between or among the individual variables as the series of variables exhibits a unit root process. Based on the results in Table 2, we cannot reject the null hypothesis of no cointegration. The null hypothesis cannot be rejected since the test statistic was found to be greater than the critical values (-4.9897), as proposed by Phillips \& Ouliaris (1990) at the $1 \%$ significance level. This indicates that the oil price and other variables, do not share a common trend in the long term, and hence has no long-term effects. This means that the error-correcting term consisting of wealth, income, interest and oil price does not represent any deviation from equilibrium.

Having no cointegration eliminates the existence of long-run effects but there can still be short-term effects of oil price shocks. An exogenous shock in oil prices may not have same effect on consumers' spending decisions in all countries. The empirical work of Zhang \& Broadstock (2014) was inconclusive regarding whether all the countries in their study showed short-run causality or not.

Table 2. Residual-Based Engle-Granger Test of Cointegration Results.

Null Hypothesis: No cointegration or the residual series has a unit root process

\begin{tabular}{lcc}
\hline Country & & Residual t-statistics \\
\hline Canada & $\varepsilon_{t}$ & $-3.338448^{*}$ \\
Germany & $\varepsilon_{t}$ & $-3.712659^{*}$ \\
UK & $\varepsilon_{t}$ & $-2.866132^{*}$ \\
USA & $\varepsilon_{t}$ & $-3.179087^{*}$ \\
\hline
\end{tabular}

Note: *represents a $t$-stat greater than the critical values at the $1 \%$ level.

Before reporting our VAR estimation, it is necessary to determine the number of lags to include in the model. We select the number of lags for each country based on the following criteria for lag selection: Final prediction error (FPE), Akaike information criteria (AIC) and Schwarz criteria (SC), as reported in Table 3. Each of these criteria suggested a different number of lags. The number of lags suggested by the FPE and AIC was either 5 or 6 in most cases, as opposed to the Schwarz criteria (SC), which suggested 1 lag.

For the purpose of our analysis, it makes sense to choose a large numbers of lags for two reasons. Firstly, it is worth mentioning that with VAR, the standard errors are likely to be biased by the possibility of autocorrelated error terms. Thus taking a large number of lags 
will reduce the effects of error autocorrelation and the results will be less persistent. It must also be noted that, statistically speaking, taking a large number of lags would result in a greater loss of observations through degrees of freedom, and the regression estimates might be biased.

Secondly, taking large lags also makes sense on theoretical grounds. Each lag represents a quarter, and given that there is a shock in the economy, its effect will be realized over time, which may take a few lags. Furthermore, given that central banks decide to adopt a monetary policy because of the shock, it may take some time for this to affect the macroeconomic variables. All these seem to take a large number of lags. However, we consider the test results and choose a reasonable number of lags, which also allows us not to compromise the number of observations used. Thus, the chosen numbers of lags are: 6 for Canada, 6 for Germany, 5 for the UK and 6 for the USA. We will refer to the number of lags as ' $p$ ' in subsequent VAR analysis.

Table 3. Lag Selection Criteria

\begin{tabular}{lcccc}
\hline $\begin{array}{l}\text { Country } \\
\text { SC }\end{array}$ & & & FPE & AIC \\
\hline Canada & 6 & $1.98 \mathrm{e}-17^{*}$ & $-24.36288^{*}$ & -20.42172 \\
Germany & 6 & $1.98 \mathrm{e}-17^{*}$ & $-24.36288^{*}$ & -20.42172 \\
UK & 5 & $4.21 \mathrm{e}-15^{*}$ & $-18.96543^{*}$ & -15.65994 \\
USA & 6 & $1.16 \mathrm{e}-16^{*}$ & $-22.60020^{*}$ & -18.65904 \\
\hline
\end{tabular}

Note: $*$ indicates the number of lags suggested by the particular test

Other than the minimal loss of observations, the decision regarding lag selection should also reflect whether the estimated $\operatorname{VAR}(p)$ (Note 4) model is stable and consistent with no serial correlation. Given the five set of variables for each country, the $\operatorname{VAR}(p)$ model comprises five equations, one for each variable. However, our analysis only requires us to report the effects of oil prices on consumption and hence we will only report the results from that equation. Thus our analyzed equation in the $\operatorname{VAR}(p)$ model is of the following form:

$$
\begin{aligned}
& \Delta C_{t}=a_{0}+\sum_{s=1}^{p} \Delta Y_{t-p}+\sum_{s=1}^{p} \Delta W_{t-p}+\sum_{s=1}^{p} \Delta C_{t-p}+\sum_{s=1}^{p} \Delta \text { Oilprice }_{t-p}+ \\
& \sum_{s=1}^{k} \Delta \boldsymbol{R}_{t}+\varepsilon_{t}
\end{aligned}
$$

The regression estimates of the computed $\operatorname{VAR}(p)$ model will only be able to infer the possible effects of oil prices, if the model shows stability and no serial correlation. The Breusch-Godfrey Lagrange multiplier test (LM) autocorrelation test strongly suggests that our $\operatorname{VAR}(p)$ estimates are indeed consistent with having no serial correlation.

Having established the conditions for stability and autocorrelation for our computed $\operatorname{VAR}(p)$, we can explore the inferences of the estimated coefficients and how they indicate oil price 


\section{Macrothink}

effects. For simplicity only the coefficients of oil price are reported.

It can be seen that for all the countries, the coefficients of oil price are not found to be significant for all lags. Perhaps with too many lags and too many variables, it is difficult to infer the extent to which each of these variables affects others. Thus with too many lags for a series of integrated variables, our $\operatorname{VAR}(p)$ model may limit the interpretation for all lags.

Another observation is that the signs of the coefficients are negative in most cases but positive in a few. This draws attention to whether the oil price affects consumption symmetrically or not. It is expected that a rise in oil prices should be associated with a decline in consumption for most economies. However, whether the effects are symmetric or asymmetric across periods of shocks cannot be identified from the coefficients.

Table 4. $\operatorname{VAR}(p)$ Estimates for Consumption

\begin{tabular}{|c|c|c|}
\hline Country & consumption & $t$-statistics ( $p$-values) \\
\hline \multicolumn{3}{|l|}{ Canada } \\
\hline Oil price(-1) & $0.010052 *$ & $3.097835(0.0028)$ \\
\hline Oil price(-5) & $-0.009420 *$ & $-3.127927(0.0025)$ \\
\hline \multicolumn{3}{|l|}{ Germany } \\
\hline Oil price & \multicolumn{2}{|c|}{ No significant impact } \\
\hline \multicolumn{3}{|l|}{ UK } \\
\hline Oil price & \multicolumn{2}{|c|}{ No significant impact } \\
\hline USA & & \\
\hline Oil price(-1) & $0.007181^{*}$ & $2.672700(0.0093)$ \\
\hline Oil price(-5) & $-0.009604 *$ & $-3.614545(0.0005)$ \\
\hline
\end{tabular}

The coefficients of the variable reveal little about the extent to which each lagged value of oil price may significantly impact consumption in that particular period. In this regard, we conducted a Wald test for testing the hypothesis whether the coefficients are jointly zero.

For a system of equations in the $\operatorname{VAR}(p)$ model, this test would allow us to predict if the lagged values of oil price can jointly affect the movement in a consumption series (Enders, 2004). Thus it is assumed that if the lags of oil price have some forecasting power, the coefficients of the variables will not jointly be zero. In that case, it is said that oil prices 'Granger Cause' consumption (Enders, 2004).

The test hypothesis is that the coefficient of the oil price is jointly zero. In other words, oil price coefficients do not jointly affect consumption. Hence, not rejecting the null hypothesis would mean that oil prices do not affect consumption (including other variables) and thus cannot establish short-run equilibrium.

Table 5 reports the test results and it can be seen that for all countries, the $f$-statistics were 
insignificant to be at the 5\% level except for UK and Germany. The joint test for coefficients is an indication that oil prices may have impact on consumption in the short term for Canada and the USA but not for Germany and the UK. A key question that our study tries to address is to what extent the oil price shock affects the consumption of oil-importers and oil-exporters. It should be noted that oil-exporting countries are more dependent on oil for generating revenue and they are also producing oil. Thus movement of the oil price series is expected to have stronger implications on consumption for oil-exporters than for oil importers, and further analysis is required to test this notion.

Table 5. Wald Test Results.

Null Hypothesis: All oil price coefficients are jointly zero

\begin{tabular}{lll}
\hline Country & $\boldsymbol{F}$-statistics $(\mathbf{D F})$ & Probability \\
\hline Canada & $3.492883^{*}$ & 0.0043 \\
& $(6,74)$ & \\
Germany & $\begin{array}{l}1.804830 \\
(8,62)\end{array}$ & 0.0931 \\
UK & $\begin{array}{l}1.168877 \\
(7,68)\end{array}$ & 0.3322 \\
USA & $\begin{array}{l}4.477150 * \\
(6,74)\end{array}$ & 0.0006 \\
\hline
\end{tabular}

* indicates significance at the $1 \%$ level.

Therefore, we compute the 'forecast error variance decomposition' (FEVD) as shown in Table 6.The estimates of FEVD will indicate if the time series path of consumption is explained by its own shocks and shocks in wealth, income, interest and oil prices (Enders, 2004). In other words, we can see if the oil price series makes a contribution to the forecasting error of the consumption model.

We compute the FEVD with Cholesky ordering of the $\operatorname{VAR}(p)$ specification:

$\Delta($ Consumption $) \Delta($ Wealth $) \Delta($ Income $) \Delta($ Interest $) \Delta($ Oil Price $)$.

It can be expected that it may take as long as 2years for the persistence of an oil price shock to die out and hence we compute the FEVD with 10 lags (each representing a quarter). However, again for simplicity, only the result for every second lag is represented. It can be seen that the variance decomposition of oil prices is increasing for all the countries up to a certain lag (four lags in most cases) and then remains relatively unchanged. This indicates that the oil price has some forecasting power for the movements in consumption. This is an indication that the proportion by which error variance decomposition is influenced by oil price changes increases over time for as long as four lags (each representing a quarter). Thus, the FEVD supports our assumption that oil prices can affect consumption. However, if we compare the results across countries, we see that for the case of the UK only, the oil price 
series does not seem to contribute much to the predicting the error variance. For most of the lags the percentage of contribution remains small. In the case of Germany, the interest rate seems to make the highest contribution to the forecasting error and thus poses the question whether the impact on consumption is derived mostly from oil prices or interest rates in this case.

Table 6. Forecast Error Variance Decomposition

\begin{tabular}{llcrrrr}
\hline Country & Period & $\Delta$ (Consumption) $\Delta($ Wealth $)$ & $\Delta$ (Income $)$ & $\Delta$ (Interest $)$ & $\Delta$ (Oil Price) \\
\hline Canada & 2 & 79.71825 & 7.788498 & 1.909785 & 2.181492 & 8.401971 \\
& 4 & 77.13583 & 7.606490 & 2.295571 & 3.604885 & 9.357225 \\
& 6 & 79.22409 & 5.885387 & 2.798569 & 4.422006 & 7.669947 \\
& 8 & 78.37106 & 5.851140 & 3.765931 & 4.462739 & 7.549129 \\
Germany & 10 & 80.24066 & 5.127332 & 3.631923 & 4.273175 & 6.726908 \\
& 2 & 90.24999 & 0.222398 & 0.239208 & 6.323950 & 2.964455 \\
& 4 & 77.66517 & 0.339309 & 0.868147 & 9.773579 & 11.35380 \\
& 6 & 76.16547 & 2.189021 & 2.032499 & 9.507116 & 10.10589 \\
& 8 & 69.78467 & 3.803855 & 3.174336 & 12.42740 & 10.80974 \\
UK & 10 & 66.04658 & 4.044571 & 5.839536 & 14.79048 & 9.278829 \\
& 2 & 97.20218 & 0.061533 & 1.949646 & 0.076174 & 0.710462 \\
& 4 & 83.85707 & 2.723009 & 4.610331 & 1.704102 & 7.105488 \\
& 6 & 86.78876 & 1.939309 & 4.994840 & 1.517958 & 4.759138 \\
& 8 & 83.43943 & 3.048253 & 5.752023 & 2.049051 & 5.711243 \\
& 10 & 85.09242 & 2.869035 & 5.039107 & 2.112747 & 4.886688 \\
& 2 & 88.49489 & 3.456005 & 1.130247 & 0.099514 & 6.819343 \\
& 4 & 78.14665 & 5.241342 & 7.918041 & 0.684258 & 8.009712 \\
& 6 & 66.58249 & 10.48911 & 5.945389 & 7.543142 & 9.439870 \\
& 8 & 64.62234 & 10.74096 & 6.918797 & 7.213411 & 10.50449 \\
& 10 & 66.72221 & 9.697516 & 6.269980 & 7.584030 & 9.726259 \\
\hline
\end{tabular}

Note: The Cholesky ordering used here is: $\Delta$ (Consumption) $\Delta$ (Wealth) $\Delta$ (Income) $\Delta$ (Interest) $\Delta$ (Oil Price).

However, more realistically, with too many variables involved (consumption, wealth, income, interest rate and oil price), it cannot be clearly inferred that the oil price has strong predictive power for explaining the movements of consumption series.

Thus, as an additional diagnostic step in our analysis, we extend the FEVD with a new Cholesky ordering including wealth and income variables only:

$\Delta$ (Consumption) $\Delta$ (Wealth) (Income) $\Delta$ (Oil Price),(Note 5) as shown in Table 7.

The idea behind this additional diagnostic step is that including wealth and income variables may allow provide evidence of the direct impacts of oil prices on consumption(Note 6). As Modigliani \&Brumberg (1954) acknowledged that wealth and income are the determining factors of consumption, it is expected that shocks in oil price will affect each of the variables 
in sequence.

We exclude the interest rate because it is unlikely that the oil price is the only reason for interest rate fluctuations. An oil price shock is likely to increase interest rates in the aftermath of inflation but this is not evident.

Table 7 summarizes the findings, in which we only report the results for oil prices because of its relevance. The results show that the variance decomposition for the oil price remains high and increases proportionately for more lags for Canada (14.22\%) and the USA (9.34\%). For Germany $(4.72 \%)$ and the UK $(0.39 \%)$, it remains proportionately low compared with the other two countries. In the case of Canada and the USA, the variance decomposition increases up to the sixth lag and then remains stable, indicating that the persistence of shocks arising out of oil prices starts to fade after six quarters or remains stable. If we compare our results with those in Table 6, it appears that the oil price seems to explain the forecast error variance better when the interest rate is omitted.

Table 7. Forecast Error Variance Decomposition

\begin{tabular}{llc}
\hline Country & Period & $\Delta$ (Oil Price) \\
\hline Canada & 2 & 14.22150 \\
& 4 & 14.04999 \\
& 6 & 12.50355 \\
& 8 & 12.24476 \\
Germany & 10 & 12.19032 \\
& 2 & 4.718694 \\
& 4 & 5.378220 \\
& 6 & 4.317495 \\
UK & 8 & 4.370860 \\
& 10 & 4.043119 \\
& 2 & 0.395308 \\
& 4 & 4.021663 \\
& 6 & 2.804692 \\
& 8 & 4.163302 \\
& 10 & 3.565051 \\
& 2 & 9.338782 \\
& 4 & 10.01339 \\
& 6 & 9.992394 \\
& 8 & 10.02614 \\
& 10 & 10.27434 \\
\hline
\end{tabular}

Note: The Cholesky ordering used here is: $\Delta$ (Consumption) $\Delta$ (Wealth) $\Delta$ (Income) $\Delta$ (Oil Price) 


\section{Mll Macrothink}

Following the Wald test and the FEVD test, we can now establish that oil prices have some impact on consumption at least for Canada and the USA, though the results for Germany and UK still remain inconclusive. However, none of the former tests suggest the direction of the shock. In other words, whether a unit of increase in the oil price increases or decreases consumption still remains a question. Hence, to investigate the direction, we also plot the impulse response functions (IRF) as shown in Figure $2 \mathrm{a}-2 \mathrm{e}$ to assess the impact of one unit positive shock on consumption using the Cholesky ordering: $\Delta$ (Consumption) $\Delta$ (Wealth) $\Delta$ (Income) $\Delta$ (Oil Price(Note 7)).For clarity, the accumulated response of each graphs ispresented with one Cholesky standard deviation for oil price innovations.

"An Impulse Response Function is a Vector Moving Average of a VAR model in the sense that shocks are computed in error terms "(Enders, 2004). The initial interpretation of the set of response functions is that for a unit of increase in oil price, consumption increases over the lags. Thus a positive shock to oil price innovations leads to a positive shock in wealth, income and consumption. The persistence of shock increases for consumption and income for most of the countries but it dies out after the fifth lag for the wealth series, as shown in the graphs. It is expected that a positive shock in oil price changes should lead to a decrease in consumption, along with income and wealth.

When there is an oil price increase, it is not expected that rational consumers will reduce consumption of oil instantly. They may switch to using a cheaper energy, such a gas, but this whole process takes some time. Although the effect for consumption is realized after certain lags, it is still expected that consumer's disposable income as well as accumulation of wealth will be negatively affected. It must be recalled that other than the exogenous variables in our model, there can be many other factors affecting consumption simultaneously (the omitted-variables argument can hold in this regard). However, based on the response functions, it remains inconclusive whether the positive shock in oil price is positive or negative on consumption.

Fig.1a. Accumulated Impulse Response Functions for Canada

Response of Consumption to Oil Price (WTI)

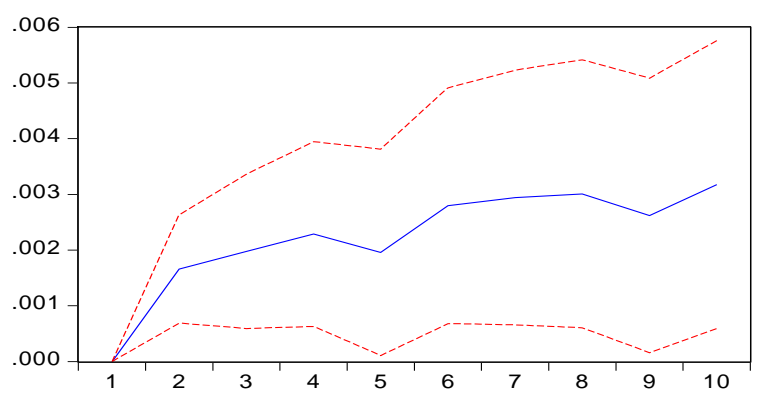

Response of Income to Oil Price (WTI)
Response of Wealth to Oil Price (WTI)

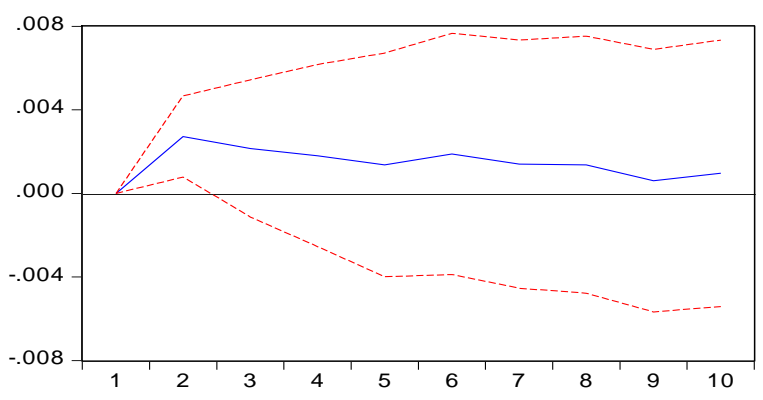

Response of Oil Price to Oil Price 

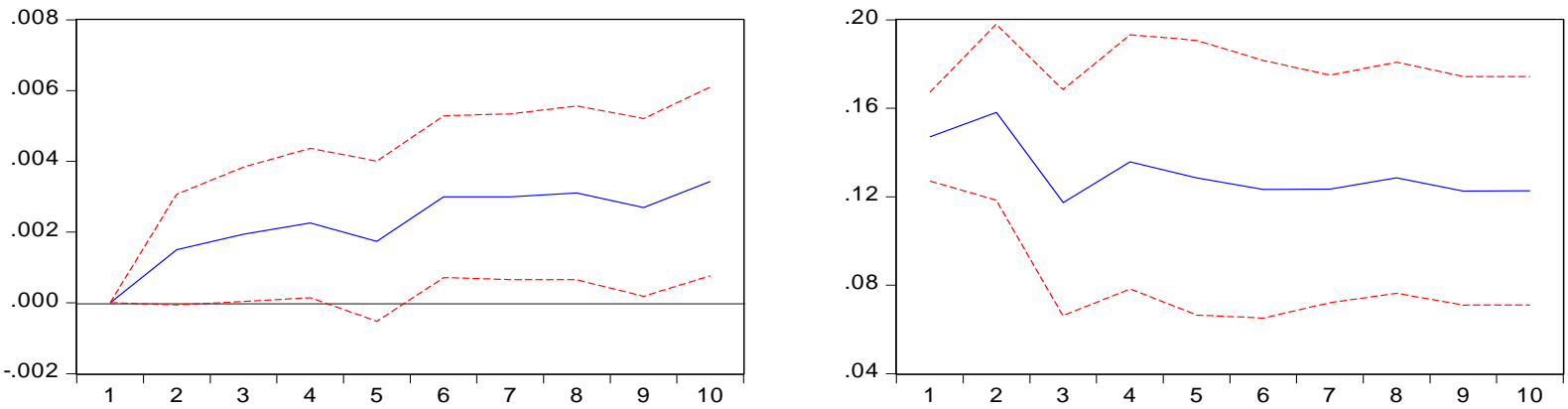

Fig.1b. Accumulated Impulse Response Functions for Germany

Response of Consumption to Oil Price (Brent)

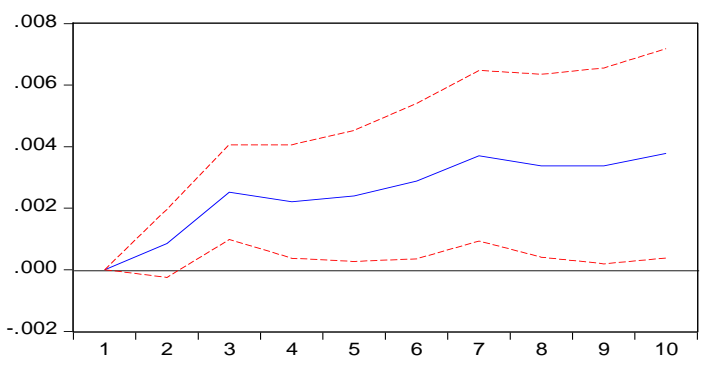

Response of Income to Oil Price (Brent)

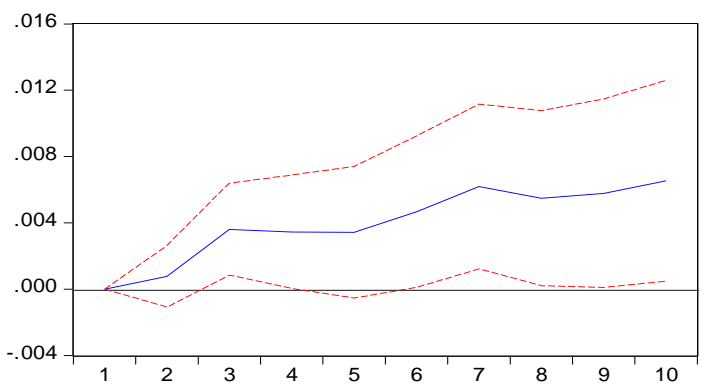

Response of Wealth to Oil Price (Brent)

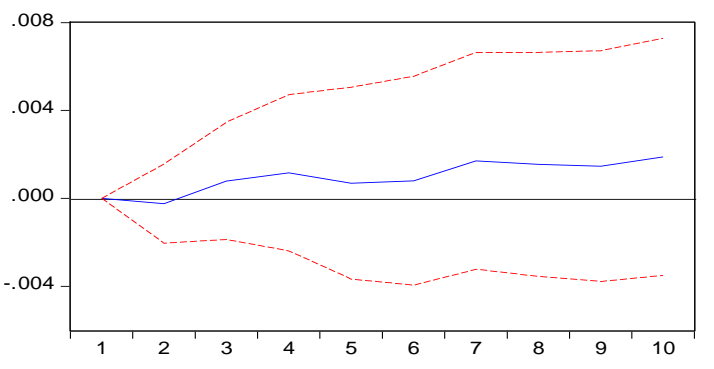

Response of Oil Price to Oil Price

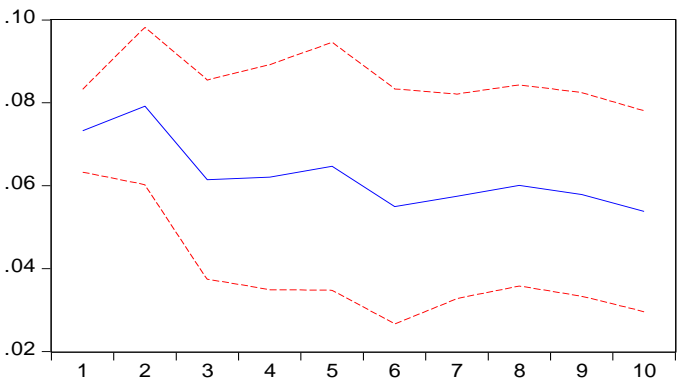

Fig.1d. Accumulated Impulse Response Functions for the UK

Response of Consumption to Oil Price (Brent) Response of Wealth to Oil Price (Brent)
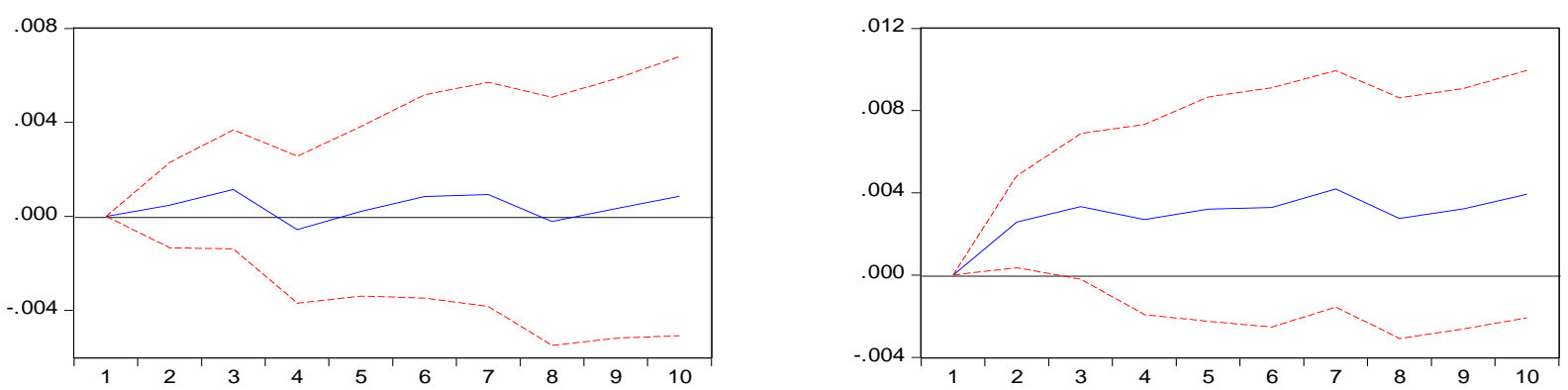

Response of Income to Oil Price (Brent) Response of Oil Price to Oil Price 

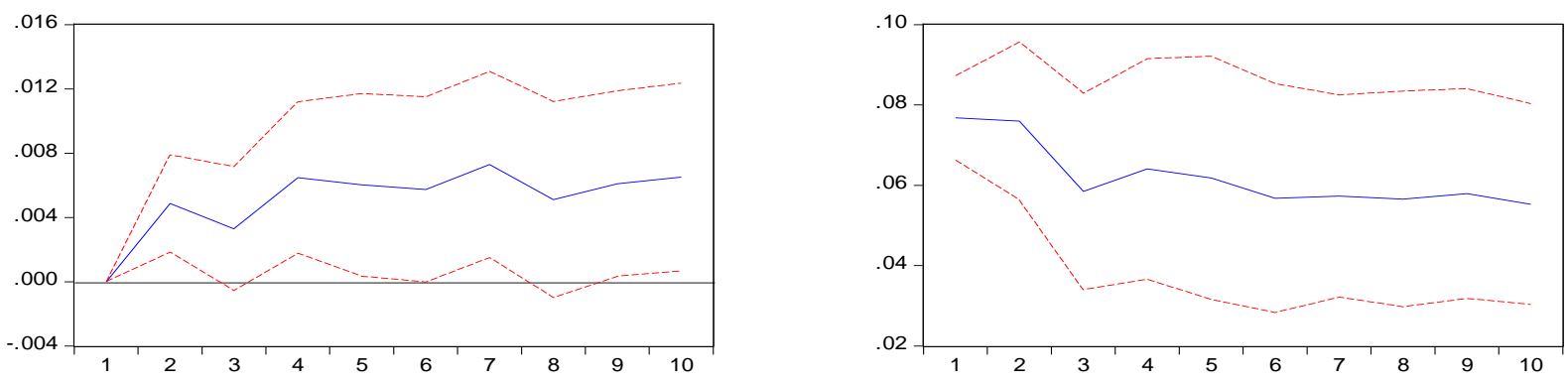

Fig. 1e. Accumulated Impulse Response Functions for the USA

Response of Consumption to Oil Price (WTI) Response of Wealth to Oil Price (WTI)
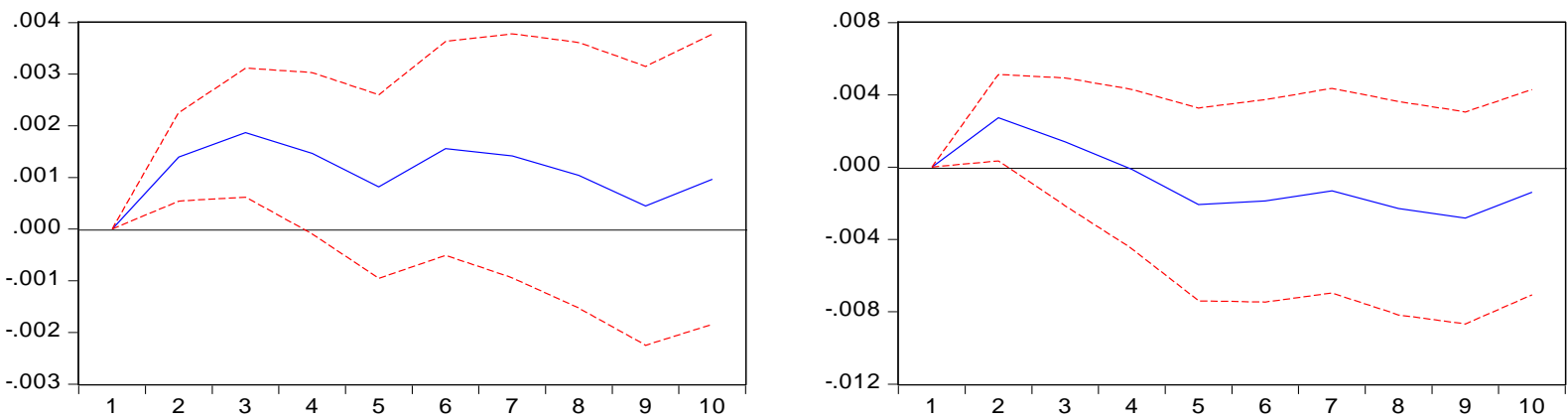

Response of Income to Oil Price (WTI)

Response of Oil Price to Oil Price
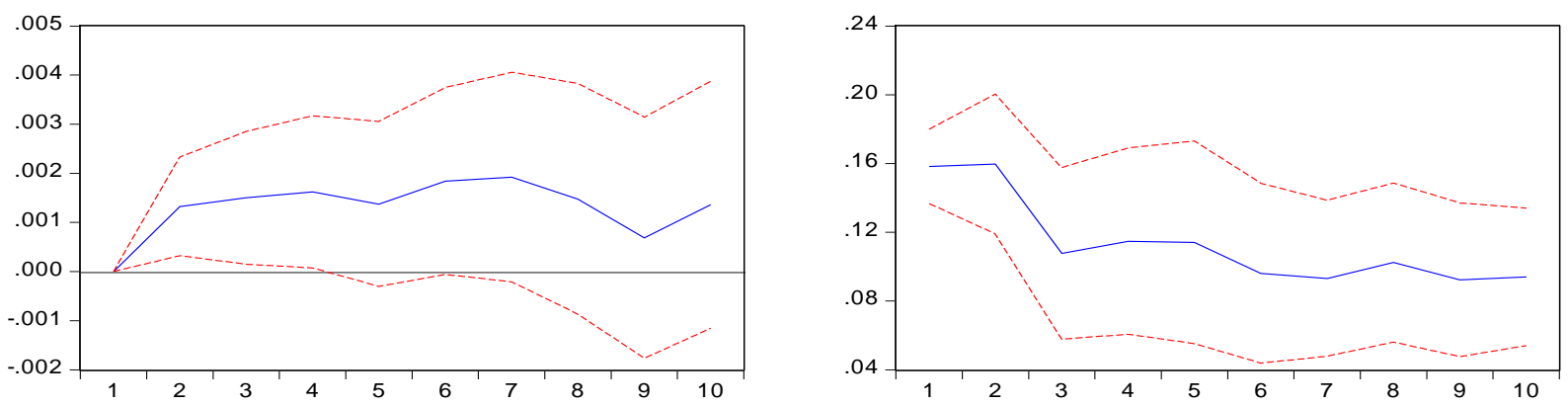

Fig. 1. Accumulated Impulse-response of consumption, wealth and income

Note: Horizontal lines shows the impulse response period and the vertical axis shows the responses to the given shock.

From our results so far, we find evidence that the economies of Canada and the USA are more responsive to shocks emerging from oil prices in the short term. The results for the UK and Germany remain inconclusive as some of the tests suggest evidence of shocks but the rest do not imply this. It must be noted that the effects of shocks purely depend on dependence on oil in that particular country. So far, our analysis agrees with conclusion of Mehra \& Petersen (2005) that for the USA, there seems to be short-term causality of oil price on consumption. Though Mehra \& Petersen (2005) conducted the study several years back using a sample size from earlier periods, the application of a recent sample produces similar results. The study by Zhang \& Broadstock (2014) also came up with similar conclusions about short-run causality. 
Their work, however, was based on ASEAN countries and, empirically, they studied two kinds of effects arising from oil price: a net positive effect and net negative effects on consumption. However, based on their estimates, they also argue that the oil price does not necessarily impact consumption for all countries.

\section{Conclusion}

The study empirically assesses if global oil price changes have any impact on household consumption. Our analysis sheds light on a few observations: first, we find evidence that oil price changes affect household consumption in our selected countries, particularly Canada and the USA but the results are inconclusive for Germany and the UK. Following the FEVD diagnosis, it can also be inferred that oil prices make a proportionately increasing contribution to the movement in consumption series. Finally, plotting the IRFs infer that the effect of a unit shock in 'Net oil price increase' on consumption is negative and the effects on consumption persist for longer. As before, our results for IRF are mostly consistent for Canada and USA and this indicates that oil prices certainly affect consumers in the oil-exporting countries. On the contrary, in Germany there is some evidence of an impact but in general, the results are mixed and inconclusive. Finally in the case of the UK, there is no evidence of either positive or negative impacts on consumption resulting from oil price innovations.

On the basis of our results, we can argue that oil price shocks may have a significant impact on the consumer spending of large oil-dependent countries, where Canada is one of the largest producers and exporters, and the USA is one of the largest consumers of oil (EIA 2015). Although the USA has changed its position from a net exporter to a net importer of oil (EIA 2015), yet oil remains an important component for the US economy.

Although Germany and the UK are among the largest importers of oil, we do not find much evidence of the effects of oil price shocks on their household consumption. The probable reason is that the dependence of these countries on oil has substantially decreased over recent years and, in regard to interest rate changes, there has been very little change over the last few decades for these two countries. In the context of Germany, imports of oil from Russia have considerably reduced as Germany switched into gas consumption. The $\sim 23 \%$ of energy imports from Russia consist of roughly less than one-third of Germany's oil imports. Hence for Germany, there has been a net change from oil consumption to gas consumption. Our forecast error decomposition in the first analysis also shows that oil alone does not have much predictive power in the context of UK and Germany.

Another observation that came up is that interest rates play an insignificant role in affecting consumption, at least in the short term. The FEVD without the interest rate variable gave better results in this regard. Thus one cannot really argue that adoption of a monetary policy in the aftermath of an oil price shock has an influence on consumption, at least in the short term.

Moreover, the theory of rational expectation suggests that when there is a major shock in the 
economy, consumers' expectations about the future tend to impact their planned consumption and hence their current consumption. For an oil-dependent country, the rational expectations of consumers are likely to change more than in countries depending less on oil. But this theoretical argument may not be relevant in the real world. For instance, it is difficult to classify what actually causes changes in the interest rates. Canada and the USA have been inflation-targeting economies since the 1970s, one can argue that these economies are more likely to be responsive to oil price shocks. But it is also true that the central banks in these countries may also decide to reduce interest rates for other reactions such as reducing unemployment. Thus, practically speaking, it is rather difficult to determine the actual cause of interest rate fluctuations around a given period. In other words, a more sensible argument could be that in the real world one shock does not occur 'ceteris paribus' to other factors; instead, it is more realistic to have many exogenous shocks occurring or working together simultaneously.

It should also be noted that there could be other factors that contribute to the effects on consumption other than the independent parameters considered in our model. This omitted variable bias is likely to create heteroscedastic effects in the model, which, to some extent, is reflected in the large $R^{2}$ values for each model. Further research may help to shed light on these aspects.

However, the direct implications of an oil price increase still remain debatable, as fuel use for transportation varies substantially for different countries. For instance, the UK's dependence on oil still remains high because of its high use in the transportation sector. However, within the Euro zone, dependence on oil varies a lot. Beside the transport sector, the use of oil remains high in the industrial sector. In the case of the UK and Germany, industry has shifted from petroleum-intensive to gas-intensive products over recent decades. Thus despite the fact that most industrialized countries have switched their production from oil-intensive to gas-intensive products, the use of crude oil still remains important for many countries because its use cannot be completely eliminated from the energy market.

Finally, going back to our overall findings, an important implication is that it remains inconclusive as to how the oil price affects consumer decisions for Germany and the UK. The dependence of the Euro zone on oil has fluctuated a lot over the last few decades. In the context of Germany, the imports of oil from Russia have reduced considerably as Germany switched to gas consumption. The $\sim 23 \%$ of energy imports from Russia consist of roughly one-third of Germany's oil imports. Hence for Germany, there has been a net change from oil consumption to gas consumption. Similarly, the UK has also lowered its oil dependence since the large global recession in 2008. For the UK, the economy's dependence on oil is mainly its heavy use in the transport sector; though the country was a net oil exporter in 2008. Total energy consumption stood nearly $38 \%$ for oil and $35 \%$ for natural gas. Thus, for the UK, both oil and gas play a significant role in private sector consumption, and the substitution of gas for oil within energy consumption has made oil a less important component over the past few years.

Because of the limitations of this study, our analysis includes oil as the only form of energy 
affecting consumption. However, as some oil-importing countries have switched into using other forms of energy sources, further studies should be conducted that can give a clear indication whether energy has the power to influence household consumption.

\section{Acknowledgement}

This paper was originally written as part of my Master thesis at Lund University, Sweden. I would like to thank my supervisors, Klas Fregert (Associate Professor) and Joakim Westerlund (Professor), at Department of Economics for their valuable time and guidance throughout the process. Finally it is worth mentioning that I will always be grateful to Swedish Institute and Swedish Government for awarding me this excellent scholarship without which my Master Program at Lund would not have been possible.

\section{References}

Blanchard, O., \& Galí, J. (2007). The Macroeconomic Effects of Oil Price Shocks: Why are the 2000s so Different from the 1970s?. SSRN Electronic Journal. https://doi.org/10.2139/ssrn.1008395

Enders, Walter. (2004). Applied Econometric Time Series. Technometrics, 46(2), 264-264. https://doi.org/10.1198/tech.2004.s813

Engle, Robert F., \& C. W. J. Granger. (1987). Co-Integration And Error Correction: Representation, Estimation, And Testing. Econometrica, 55(2), 251. https://doi.org/10.2307/1913236

Ezez. (2018). Eia.gov. Retrieved from https://www.eia.gov/opendata.

Ezez. (2018). "Federal Reserve Bank of St. Louis". FRED home page. Retrieved from https://fred.stlouisfed.org.July

Ezez. (2018). Oxford Economics Secure Login. Retrieved from Services.oxfordeconomics.com

Gylfason, Thorvaldur. (1981). Interest Rates, Inflation, and the Aggregate Consumption Function. The Review of Economics and Statistics, 63(2), 233. https://doi.org/10.2307/1924094

Hamilton, James D. (2009). Causes and Consequences of the Oil Shock of 2007-08. SSRN Electronic Journal. Elsevier BV. https://doi.org/10.2139/ssrn.2583456

Herrera, Ana María, Latika Gupta Lagalo \& Tatsuma Wada. (2015). Asymmetries In The Response Of Economic Activity To Oil Price Increases And Decreases?. Journal Of International Money And Finance, 50, 108-133. https://doi.org/10.1016/j.jimonfin.2014.09.004 
Jiménez-Rodríguez, Rebeca \& Marcelo Sánchez. (2005). Oil Price Shocks And Real GDP Growth: Empirical Evidence For Some OECD Countries. Applied Economics, 37(2), 201-228. https://doi.org/10.1080/0003684042000281561

Kilian, Lutz. (2008). The Economic Effects of Energy Price Shocks. Journal of Economic Literature, 46(4), 871-909. https://doi.org/10.1257/jel.46.4.871

Mehra, Yash P. (2005). Oil prices and consumer spending. Economic Quarterly, 3(91). Federal Reserve Bank of Richmond.

Mishkin, Frederic S. (1976). Illiquidity, Consumer Durable Expendi- ture, and Monetary Policy. The American Economic Review, 66(4), 642-54.

Modigliani, Franco \& Brumberg, Richard. (1954). Utility analysis and the consumption function: an interpretation of cross-section data. [S.1.]: [s.n.].

Mork, Knut Anton. (1989.) Oil and the Macroeconomy When Prices Go Up and Down: An Extension of Hamilton's Results. Journal of Political Economy, 97(3), 740-744. https://doi.org/10.1086/261625

Phillips, P. C. B., \& Ouliaris, S. (1990). Asymptotic Properties of Residual Based Tests for Cointegration. Econometrica, 58(1), 165. https://doi.org/10.2307/2938339

Sørensen, Peter Birch \& Whitta-Jacobsen, Hans Jørgen. (2010.) Introducing advanced macroeconomics. Maidenhead: McGraw-Hill Education.

Springer, William L. (1975). Did the 1968 surcharge really work?. The American Economic Review, 65(4), 644-659.

Weber, Warren E. (1970). The Effect of Interest Rates on Aggregate Consumption. The American Economic Review, 60(4), 591-600.

Zhang, Dayong \& Broadstock, David C. (2014). Impact of International Oil Price Shocks on Consumption Expenditures in ASEAN and East Asia. Chapter 13. Chengdu: Research institute of Economics and Management, Southwestern University of Finance and Economics.

\section{Notes}

Note 1 . The selection of these countries is partly because of the availability of data on the variables used for this study.

Note 2. It must be noted that substitution of the equation of planned consumption (Eq.1) is reflected in the error-correcting term $\left(\left(a_{0}+a_{1} Y_{t}+a_{2} W_{t}\right)-c_{t-1}\right)$, which is then simplified to $\left(\left(a_{0}+a_{1} Y_{t-1}+a_{2} W_{t-1}+a_{3} r_{t-1}+a_{4} O i l_{\text {Price }_{t-1}}\right)-c_{t-1}\right)$. We implicitly assume that if the oil price and interest rates are included in the model, then, by the definition of a Vector Error Correcting Model (VECM), these variables will also be present in the error-correcting term 


\section{Macrothink}

as long as they exhibit long-run equilibrium.

Note 3. The question remains as to what extent monetary policy changes could reflect the effects caused by international oil price changes. The international oil price is very perception-driven and thus may not impact the monetary policy adopted by all countries in general, which will be reflected in our further empirical analysis.

Note 4. Here, ' $p$ ' represents the number of lags in the model.

Note 5. Since the reported Cholesky ordering is not our actual model to be estimated but it's an additional diagnosis, we do not report the VAR estimates and the corresponding stability tests here.

Note 6. It is assumed that if the oil price increases, the marginal propensity of consumption will increase as consumers will spend proportionately more of their disposable income. Thus consumption as well as income will fall as a result of an oil price increase.

Note 7. It should be mentioned that we plot the IRFs with respect to the Cholesky ordering: $\Delta$ (Consumption) $\Delta$ (Wealth) $\Delta$ (Income) $\Delta$ (Interest) $\Delta$ (Oil_Price ) as our VAR $(p)$ model suggests. However, the responses of interest rates to oil price were ambiguous and hence were dropped. Instead, we compute the Cholesky ordering shown in Table 8.

\section{Copyright Disclaimer}

Copyright for this article is retained by the author(s), with first publication rights granted to the journal.

This is an open-access article distributed under the terms and conditions of the Creative Commons Attribution license (http://creativecommons.org/licenses/by/3.0/). 